\title{
A Decade of CALIPSO Observations of Asian and Saharan Dust Properties near Source and Transport Regions
}

\author{
Ali Omar \\ NASA Langley Research Center, Hampton, VA 23681, USA
}

\begin{abstract}
The lidar on the Cloud-Aerosol Lidar and Infrared Pathfinder Satellite Observations (CALIPSO) mission, makes robust measurements of dust and has generated a length of record that is significant both seasonally and inter-annually. We exploit this record to determine a multi-year climatology of the properties of Asian and Saharan dust, in particular seasonal optical depths, layer frequencies, and layer heights of dust gridded in accordance with the Level 3 data products protocol between 2006 and 2016. The data are screened using standard CALIPSO quality assurance flags, cloud aerosol discrimination (CAD) scores, overlying features and layer properties. To evaluate the effects of transport on small-scale phenomena such as morphology, vertical extent and size of the dust layers, we compare probability distribution functions of the layer integrated volume depolarization ratios, geometric depths and integrated attenuated color ratios near the source to the same distributions in the far field or transport region. To evaluate the uncertainty in the lidar ratios, we compare the values computed from dust layers overlying opaque water clouds, considered accurate, with the constant lidar ratio value used in the CALIOP algorithms for dust
\end{abstract}

\section{Introduction}

CALIPSO is collaboration between NASA and Centre National d'Études Spatiales (CNES), was launched in April 2006 to provide vertically resolved measurements of cloud and aerosol distributions $[14 ; 15]$. The primary instrument on the CALIPSO satellite is the Cloud-Aerosol Lidar with Orthogonal Polarization (CALIOP), a nearnadir viewing two-wavelength polarization-sensitive instrument. CALIOP is particularly well suited to the identification and observation of mineral dust due to its sensitivity to non-spherical particles which is manifested in the depolarization measurements. A depolarized profile is returned when light interacts with a non-spherical particle $[8 ; 4 ; 9 ; 10 ; 3 ; 11 ; 1 ; 2]$. Taklimakan desert dust shows depolarizations of $15-25 \%$ with typical values of $23 \%$ during dust storms [6]. CALIPSO uses a $20 \%$ threshold for to identify pure dust particles and a 7.5\% threshold for polluted dust particles.

Mineral dust affects the Earth's radiative balance and its distribution and has important consequences in both past, current and future climate systems. Dust directly forces the radiative balance by absorbing and scattering radiation, and indirectly by acting as cloud condensation nuclei and ice nuclei. It also alters the atmospheric heating profiles in such a way that it impacts cloud distributions. To effectively study dust and its impact, a global distribution of dust and its vertical resolution is needed. An instrument that provides such data is a Light Detection and Ranging (LIDAR) profiler based on a free flying orbiter. The CALIOP instrument on the CALIPSO satellite is just such an instrument.

Lidar is a powerful tool for studying the vertical distribution of aerosols and clouds in the atmosphere. The deployment of CALIPSO has enabled vertically resolved measurements of dust and provides significant insights into properties of Saharan and Asian dust aerosols. CALIOP is designed to acquire vertical profiles of elastic backscatter at two wavelengths (1064 $\mathrm{nm}$ and $532 \mathrm{~nm}$ ) from a near nadir-viewing geometry during both day and night phases of the orbit. In addition to the total backscatter at the two wavelengths, CALIOP also provides profiles of linear depolarization at $532 \mathrm{~nm}$. Accurate aerosol and cloud heights and retrievals of extinction coefficient profiles are derived from the total backscatter measurements [13]. The depolarization measurements enable the discrimination between ice clouds and water clouds [5] and the identification of nonspherical aerosol particles [7]. Additional information, such as estimates of particle size for the purpose of discriminating between clouds and aerosols, are obtained from the ratios of the signals obtained at the two wavelengths. On April 28, 2006, the CALIPSO satellite was launched into a low earth sun-synchronous orbit at a $705-\mathrm{km}$ altitude, and an inclination of 98.2 degrees. CALIPSO's measurements of dust properties are robust and the length of the record is significant both seasonally and inter-annually.

\footnotetext{
* Corresponding author: Ali.H.Omar@nasa.gov
} 


\section{Asian and Sahara Dust Distributions near the Source and Transport Regions}

For the purposes of this study, the Asian source region is defined as the area bounded by Latitudes $(33 \mathrm{~N}-43 \mathrm{~N})$ and Longitudes (100E-110E). The Asian dust transport region is defined by same latitudes and Longitudes (110E-160E). The Saharan dust source region is defined by Latitudes $(0 \mathrm{~N}-40 \mathrm{~N})$ and Longitudes $(20 \mathrm{~W}-20 \mathrm{E})$ and the transport region is bounded by latitudes $(0 \mathrm{~N}-40 \mathrm{~N})$ and Longitudes $(20 \mathrm{~W}-80 \mathrm{~W})$. Figure 1 shows the monthly mean of the dust aerosol optical depth.
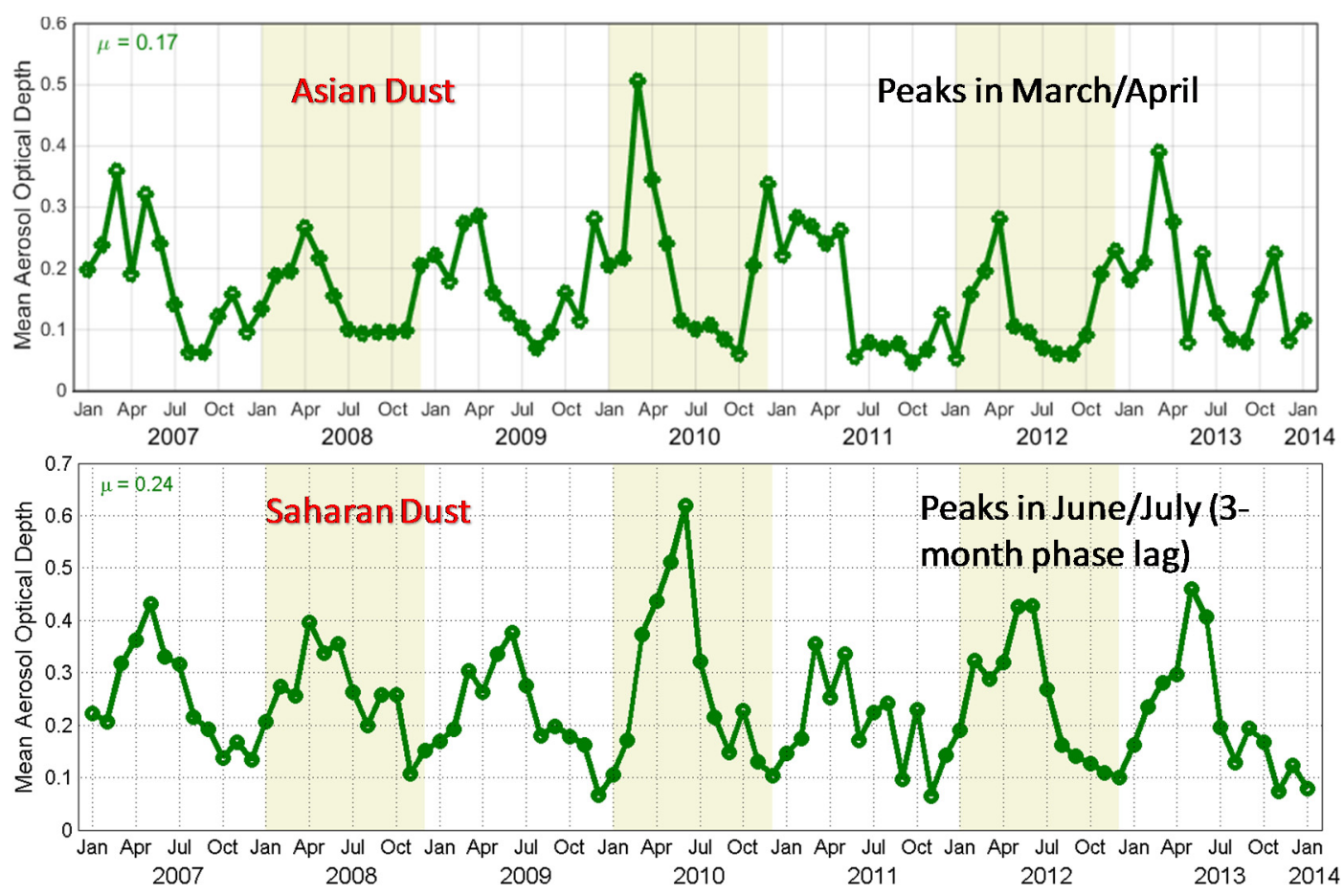

Figure 1. Dust aerosol optical depth trends for Asian and Saharan dust between 2007 and 2014.
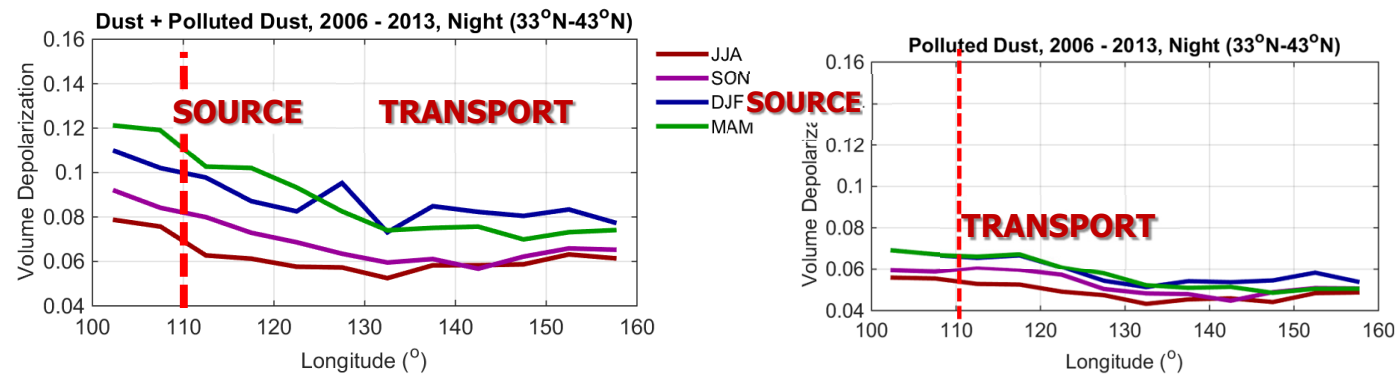

Figure 2. Volume depolarization ratios of dust and polluted dust at Source and Transport regions for Asian dust.

For both dust sources, the 2010 was a year of particularly strong dust emission. The mean dust optical depth of the Saharan dust (0.24) is larger than the Asian dust optical depth (0.17). Figure 2 shows the change in depolarization ratios of polluted dust as it is transported away from the source. There are seasonal dependencies in the particle shape manifested in differences in the volume depolarization ratios - these diminish with distance from the source. Compared with the African dust, Asian dust exhibits large variations in the intrinsic optical properties due partly to mixing with other types of aerosols when passing over the industrial regions in East Asia. Both dust particle depolarization ratios and lidar ratios show relatively large variations and inhomogeneity. Asian dust AOD peaks in March-May lead the Saharan dust AOD peaks by 3 months

Saharan dust emissions are approximately $40 \%$ stronger than Asian Dust if AOD is used as a proxy for emissions. Sahara AOD and ENSO circulation appear correlated in the years 2009-2012. Saharan dust depolarization ratio reduced below 0.075 due to mixing with other species as it that reaches the Americas in DJF and MAM. Mean dust particulate depolarization and effective lidar ratios of $0.28 \pm 0.05$ and $44 \pm 9 \mathrm{sr}$, respectively for Saharan dust. 


\section{Case Studies - Long-range Transport of Asian Dust}

Figure 3 is a case study of the long range transport of dust from Asia to the United States. Transpacific transport of Asian dust is driven by westerly winds and extends into the upper troposphere, unlike transatlantic transport of African dust which is driven by easterly trade winds and is generally confined to lower altitudes. Frequent dust emissions occurred in northwestern China in April 2010 because of stronger-than average near surface winds. Strong stable westerly winds then carried the dust eastward across the Pacific Ocean. A negative pressure anomaly, located in the eastern Pacific Ocean, hindered the air flow movement and yielded multiple transport pathways. This situation resulted in the complex yet spatially extensive dust structure over the North America. [12]. Negative pressure anomaly, located in the eastern Pacific Ocean led to complex flow. The main branch of the dust was transported into the Arctic, and looped back into the US Midwest. The southern branch was transported zonally into the western US. The long range transport of dust was observed by CALIOP during seven nighttime orbit passes. The lidar ratios show an evolution of the composition of the dust during transport. CALIPSO captures the complex properties of the aerosol mixture and vertically resolved and speciated layers. The observations show that dust is mixed with pollution during transport and that polluted dust is transported at lower altitudes while dust can reach altitudes of up to $10 \mathrm{~km}$ in the western Pacific allowing for long range transport of pure dust.

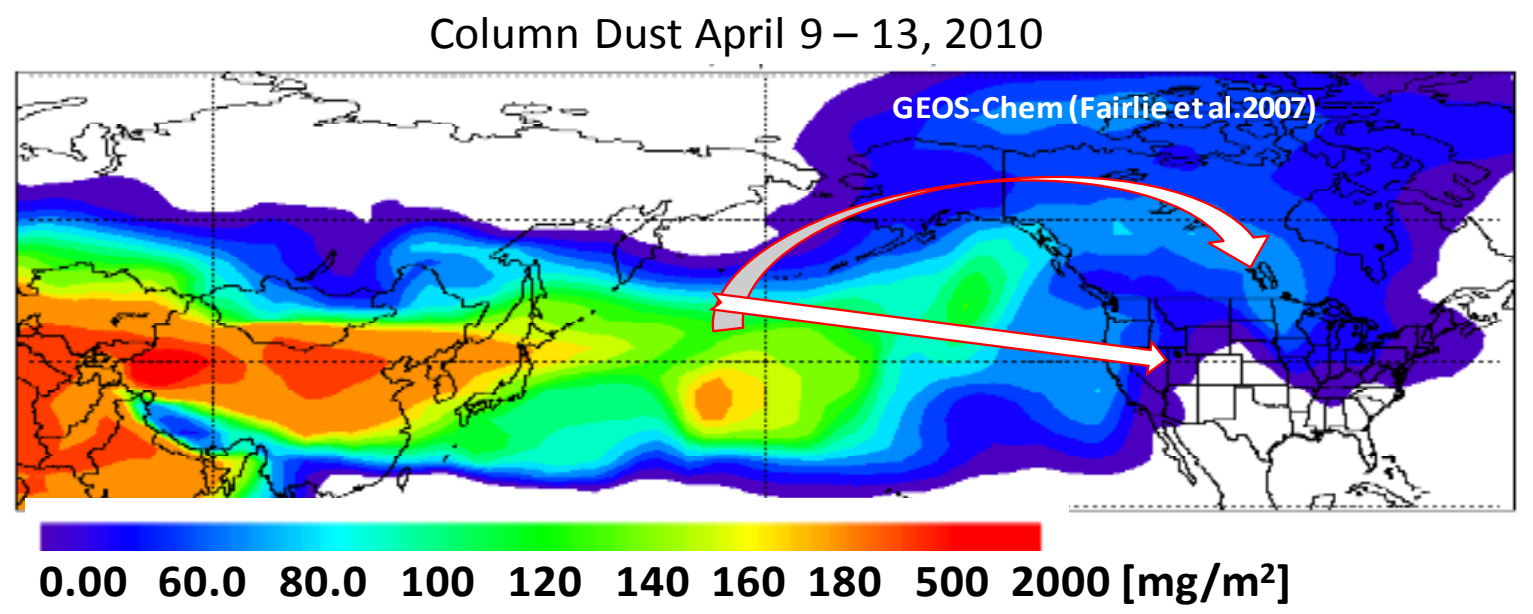

Figure 3. The Asian dust is transported by westerly winds into the upper troposphere.

\section{Conclusion}

Lidar measurements of Saharan and Asian dust optical properties near source regions and during transport have been used to study the evolution of dust as it mixes with other pollutants during transport. Compared to African (Saharan) dust, Asian dust shows significantly more mixing with pollution sources as it is transported to the western Pacific and the United States. This is expected as the dust is transported over heavily polluted regions of Asia. On an annual basis, the Saharan dust emission is larger based on a comparison of the mean dust optical depth of the Saharan dust $(A O D=0.24)$ and the Asian dust optical depth $(\mathrm{AOD}=0.17)$. Saharan dust emissions are approximately $40 \%$ stronger than Asian Dust if AOD is used as a proxy for emissions. The year 2010 showed the largest dust AOD and most likely the strongest dust emission from both regions.

\section{References}

1. A. Ansmann, H. Baars, M. Tesche, D. Muller, D. Althausen, R. Engelmann, T. Pauliquevis, and P.
Artaxo, Dust and smoke transport from Africa to South America: Lidar profiling over Cape Verde and the Amazon rainforest. Geophysical Research Letters. 36, 5 (2009)

2. A. Ansmann, A. Petzold, K. Kandler, I. N. A. Tegen, M. Wendisch, D. Müller, B. Weinzierl, T. Müller, and J. Heintzenberg, Saharan Mineral Dust Experiments SAMUM-1 and SAMUM-2: what have we learned? Tellus B. 63, 403-429 (2011)

3. F. Barnaba and G. P. Gobbi, Modeling the aerosol extinction versus backscatter relationship for lidar applications: Maritime and continental conditions. $J$. Atmos. Ocean Tech., 21, 428-442 (2004)

4. G. P. Gobbi, F. Barnaba, R. Giorgi, and A. Santacasa, Altitude-resolved properties of a Saharan dust event over the Mediterranean. Atmos. Environ., 34, 51195127 (2000)

5. Y. Hu, D. Winker, M. Vaughan, B. Lin, A. Omar, C. Trepte, D. Flittner, P. Yang, S. L. Nasiri, B. Baum, W. Sun, Z. Liu, Z. Wang, S. Young, K. Stamnes, J. Huang, R. Kuehn, and R. Holz, CALIPSO/CALIOP Cloud Phase Discrimination Algorithm. J. Atmos. Oceanic Technol., 26, 2293-2309 (2009) 
6. K. Kai, Y. Nagata, N. Tsunematsu, T. Matsumura, H. S. Kim, T. Matsumoto, S. J. Hu, H. F. Zhou, M. Abo, and T. Nagai, The structure of the dust layer over the Taklimakan desert during the dust storm in April 2002 as observed using a depolarization lidar. $J$. Meteorol. Soc. Japan. 86, 1-16 (2008)

7. Z. Y. Liu, M. Vaughan, D. Winker, C. Kittaka, B. Getzewich, R. Kuehn, A. Omar, K. Powell, C. Trepte, and C. HostetlerThe CALIPSO Lidar Cloud and Aerosol Discrimination: Version 2 Algorithm and Initial Assessment of Performance. J. Atmos. Oceanic Technol., 26, 1198-1213 (2009)

8. T. Murayama, H. Okamoto, N. Kaneyasu, H. Kamataki, and K. Miura, Application of lidar depolarization measurement in the atmospheric boundary layer: Effects of dust and sea-salt particles. J. Geophys. Res., 104, 31781-31792 (1999)

9. J. A. Reagan, K. J. Thome, and D. M. Powell, Lidar Aerosol Ratio: Measurements and Models. International Geosciences and Remote Sensing Symposium (IGARSS), Sidney, Australia (2001)

10. T. Sakai, T. Shibata, K. Hara, M. Kido, K. Osada, M. Hayashi, K. Matsunaga, and Y. Iwasaka, Raman lidar and aircraft measurements of tropospheric aerosol particles during the Asian dust event over central Japan: Case study on 23 April 1996. J. Geophys. Res., 108, 4349 (2003)

11. N. Sugimoto and C. H. Lee, Characteristics of dust aerosols inferred from lidar depolarization measurements at two wavelengths. Applied Optics. 45, 7468-7474 (2006)

12. I. Uno, K. Eguchi, K. Yumimoto, Z. Liu, Y. Hara, N. Sugimoto, A. Shimizu, and T. Takemura, Large Asian dust layers continuously reached North America in April 2010. Atmos. Chem. Phys., 11, 7333-7341 (2011)

13. M. A. Vaughan, K. A. Powell, R. E. Kuehn, S. A. Young, D. M. Winker, C. A. Hostetler, W. H. Hunt, Z. Y. Liu, M. J. McGill, and B. J. Getzewich, Fully Automated Detection of Cloud and Aerosol Layers in the CALIPSO Lidar Measurements. J. Atmos. Oceanic Technol., 26, 2034-2050 (2009)

14. D. M. Winker, W. H. Hunt, and C. A. Hostetler, Status and Performance of the CALIOP Lidar. SPIE Int. Soc. Opt. Eng., Maspalomas, Gran Canaria, Spain, SPIE, 8-15 (2004)

15. D. M. Winker, M. A. Vaughan, A. Omar, Y. Hu, K. A. Powell, Z. Liu, W. H. Hunt, and S. A. Young, Overview of the CALIPSO Mission and CALIOP Data Processing Algorithms. J. Atmos. Oceanic Technol., 26, 2310-2323 (2009) 